\title{
Case report. Prolaberend leiomyoom van de blaas
}

\author{
Tahnee de Vringer ${ }^{1}$ John B. W. Rietbergen ${ }^{2}$ Niels J. van Casteren ${ }^{1}$
}

Published online: 20 February 2018

(c) The Author(s) 2018. This article is an open access publication.

\section{Samenvatting}

In dit case report wordt de acute presentatie van een leiomyoom van de blaas bij een 62-jarige vrouw besproken. De patiënte presenteert zich op de Spoedeisende Hulp (SEH) met hevige pijn in de rechterflank en prolapsgevoel. Zij had de blaastumor via de urethra naar buiten geperst, waardoor het rechterostium naar beneden was getrokken. Na chirurgische resectie van de tumor verdwenen de pijnklachten.

Trefwoorden leiomyoom $\cdot$ goedaardige blaastumor

\section{Case report. Prolapsing leiomyoma of the bladder}

\begin{abstract}
In this case report, the uncommon acute presentation of a leiomyoma of the bladder in a 62-year old female is discussed. The patient presented with severe pain and prolapse into the urethra. She had pushed the tumour outwards, resulting in a downward motion of the right ureteral orifice. The tumour is successfully resected, with immediate pain relief.
\end{abstract}

Keywords leiomyoma $\cdot$ benign bladder tumour

\section{Introductie}

Een leiomyoom van de blaas is een zeldzame, maar benigne tumor die het meest voorkomt bij vrouwen met een gemiddelde leeftijd van 40 jaar [1]. Het betreft een gladwandige en homogene tumor, die klachten kan geven van frequency, hematurie, obstructieve mictie en zelfs acute urineretentie.

Het is de meest voorkomende benigne blaastumor, maar vormt slechts $0,43 \%$ van alle blaastumoren [2]. De tumor bestaat uit glad spierweefsel en gaat uit van de submucosa [3]. Bij een tumor met dit aanzicht zal pathologisch onderzoek moeten uitwijzen of het om een leiomyoom of een maligne leiomyosarcoom gaat, waarbij het sarcoom de neiging heeft om door te groeien in de muscularis propria [4].

dr. Niels J. van Casteren

nvcasteren@ysl.nl

1 afdeling Urologie, IJsselland Ziekenhuis, Capelle aan den IJssel, Nederland

2 afdeling Urologie, Franciscus Gasthuis \& Vlietland, Rotterdam, Nederland
Er bestaan veel theorieën over de etiologie van het leiomyoom van de blaas en de predominantie bij vrouwen. Een hoge expressie van oestrogeenreceptoren in leiomyomen van de blaas zou de hogere incidentie bij vrouwen kunnen verklaren [1]. Cornella et al. wijden de verhoogde incidentie bij vrouwen juist aan een verhoogde detectie door frequenter gebruik van transvaginale echografie [2]. Chronische inflammatie van glad spierweefsel zou ook een rol kunnen spelen in het ontstaan van deze benigne afwijking [1].

De behandeling van het leiomyoom bestaat uit chirurgische resectie, die open, laparoscopisch of transurethraal kan plaatsvinden, afhankelijk van de grootte en de locatie van de tumor. Er is maar één casus bekend waarbij een recidief opnieuw chirurgisch moest worden verwijderd [5].

\section{Casus}

Een 62-jarige vrouw presenteert zich op de polikliniek met bloed op het toiletpapier bij het afvegen na mictie. De urine zelf is helder. Ze heeft de afgelopen twee jaar viermaal een urineweginfectie doorgemaakt, waarvoor ze nu 


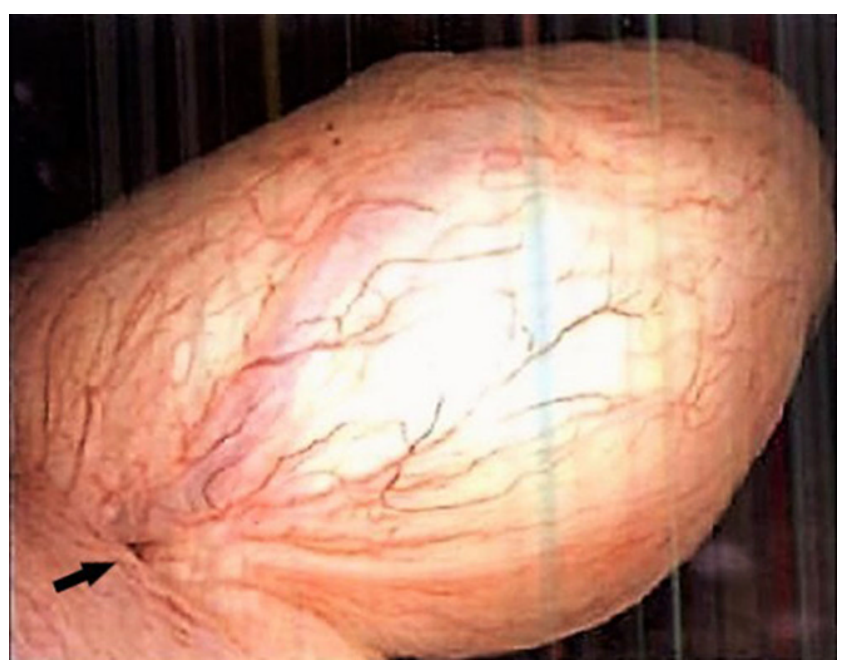

Figuur 1 Niet-papillaire afwijking in de blaas tijdens cystoscopie. De zwarte pijl geeft het rechterostium aan

een onderhoudskuur nitrofurantoïne gebruikt. Behoudens een medicamenteus behandelde hypertensie heeft ze een blanco voorgeschiedenis. Ze is vijf jaar geleden gestopt met roken.

Tijdens cystoscopie wordt een niet-papillaire afwijking ter hoogte van het rechterostium gezien (fig. 1). Het urinesediment toont $4 \pm$ erytrocyten en $2 \pm$ leukocyten en uit de urinekweek komt een mengflora. Voor verdere diagnostiek wordt een transurethrale resectie (TUR) van de blaas afgesproken.

Drie dagen later presenteert patiënte zich 's nachts op de Spoedeisende Hulp (SEH). Het lukt haar niet om te plassen en ze heeft geprobeerd door middel van persen tot mictie te komen. Dit heeft geresulteerd in forse pijn in de rechteronderrug en braken. Er zijn geen abdominale verschijnselen, maar bij inspectie van de genitalia externa valt een rode zwelling van 3 bij $4 \mathrm{~cm}$ op, die uit de urethra hangt en niet te reponeren is. De afwijking is glad, pijnlijk bij palpatie en bloedt licht (fig. 2). Ze heeft een overloopblaas waarbij urine langs de zwelling naar buiten loopt. $\mathrm{Na}$ het plaatsen van een transurethrale katheter wordt patiënte opgenomen ter pijnstilling en verdere evaluatie.

De volgende ochtend wordt er met spoed een CT IVP gemaakt om de positie van de tumor ten opzichte van het ostium af te beelden. Het verslag beschrijft een aberrant in de urethra eindigende rechterureter. Echter, met de voorkennis van de blaastumor naast het ostium bij cystoscopie, lijkt het eerder een prolaps van de blaastumor te zijn die het rechterostium mee naar beneden trekt (fig. 3).

In verband met aanhoudende pijnklachten wordt de patiënte dezelfde dag nog geopereerd. Ook op de operatiekamer lukt het niet om de afwijking te reponeren. Er wordt getracht rechts een JJ-stent te plaatsen, maar het ostium wordt niet gevonden. Aangezien er geen evident urinever-

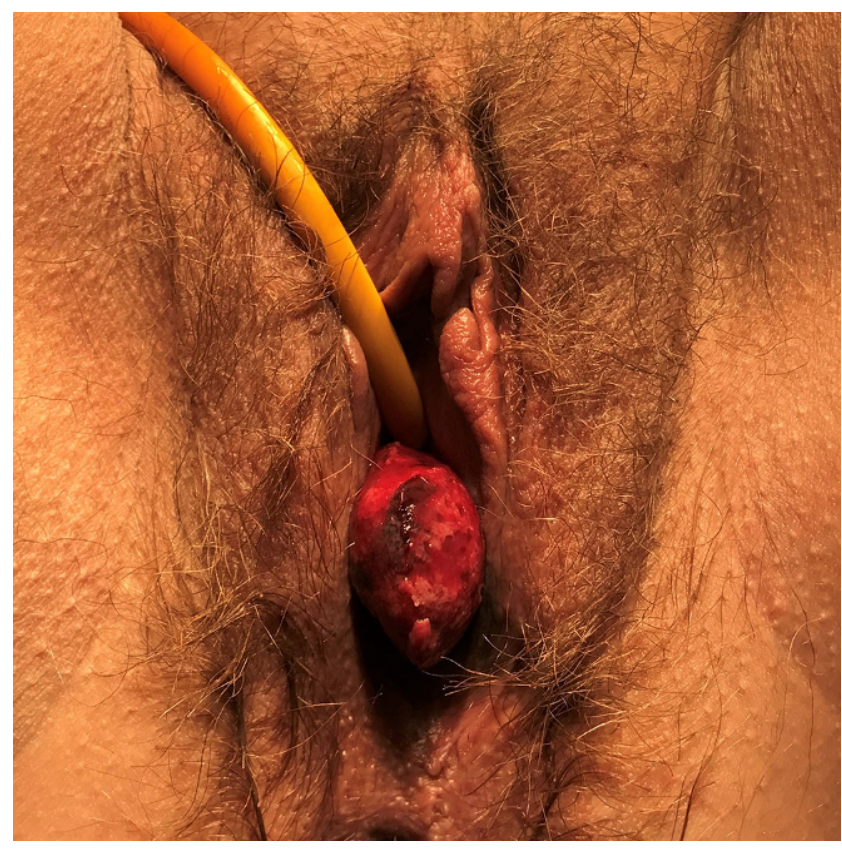

Figuur 2 Het beeld bij presentatie op de SEH, waarbij de afwijking uit de urethra hangt

lies wordt gezien, is de aanname dat het rechterostium zich nog in de blaas bevindt en niet met de afwijking naar buiten is gekomen. Derhalve wordt besloten de tumor te ligeren en door te nemen (fig. 4). De stomp kan worden gereponeerd. Hoewel het ostium hierna wel zichtbaar is, lukt het niet om een voerdraad op te voeren in de ureter. Cystoscopie laat een urine-jet uit het ostium zien en daarom wordt besloten om de bestaande situatie te accepteren. Patiënte is hierna direct pijnvrij, haar nierfunctie blijft goed en ze kan twee dagen later in goede conditie naar huis worden ontslagen.

De cytologie toont geen aanwijzingen voor hooggradige urotheelcelneoplasie en het pathologisch onderzoek laat het beeld van een leiomyoom zien. Macroscopie toont een polypeus weefselfragment, met een diameter van $3 \mathrm{~cm}$ en een dikte van $1,5 \mathrm{~cm}$. De buitenzijde is ruw en donkerbruin van kleur. Het steelgebied is wit. Op doorsnede wordt een witte haardvormige en scherp begrensde laesie gezien, met een maximale diameter van $2 \mathrm{~cm}$. Microscopische onderzoek toont leiomyomateus weefsel zonder atypie, verhoogde mitotische activiteit, necrose of vaso-invasie. Wel worden er plaatselijk oedemateuze veranderingen gezien met rondom hemorragie en vrij veel neutrofielen.

\section{Beschouwing}

Cystoscopie, echografie, CT en MRI kunnen allemaal een rol vervullen in de diagnostiek bij een leiomyoom. Desondanks heeft MRI de voorkeur, omdat deze een betere weefselkarakterisatie oplevert [3]. Uit de literatuur blijkt dat een 


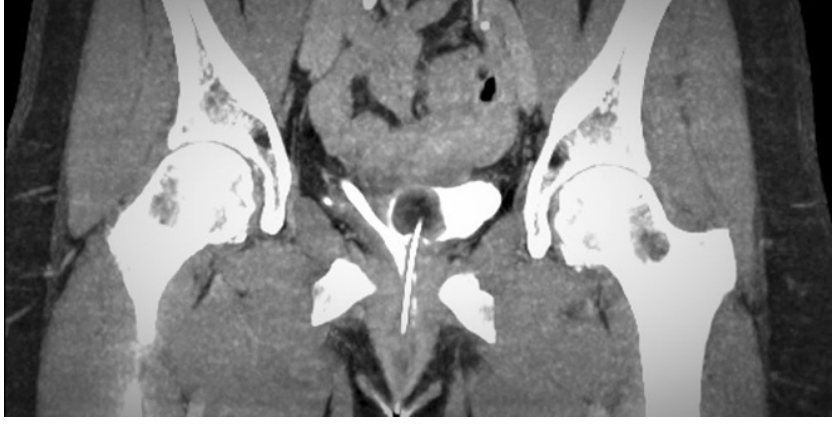

Figuur 3 CT-IVP laat zien hoe het ostium naar beneden wordt getrokken door het prolaberen van het leiomyoom

koud biopt bij $50 \%$ van de patiënten met een leiomyoom van de blaas vals-negatief is [1].

Er zijn wereldwijd minder dan 300 casus beschreven van leiomyomen die uitgaan van de blaas en maar enkele casus over een prolaps via de urethra. Wat deze casus bijzonder maakt, is dat er drie dagen voor de presentatie op de SEH alleen een afwijking in de blaas werd gezien, waarvan de aard onduidelijk was en waarvan niet vermoed kon worden dat het tot deze problematiek zou leiden. Dit acute beloop roept nog meer vragen op over de etiologie.

In tegenstelling tot een leiomyoom van de blaas, is een leiomyoom van de uterus in de westerse wereld de meest voorkomende gynaecologische tumor. Ook van deze tumor is de etiologie nog niet volledig bekend, al lijken oestrogeen en progesteron een duidelijk rol te vervullen bij de groei van het leiomyoom. Daling van de oestrogeen- en progesteronspiegel na de menopauze leidt vaak tot het slinken van het leiomyoom van de uterus. De groei van het leiomyoom bij onze postmenopauzale patiënte wijst mogelijk op een andere etiologie van het leiomyoom van de blaas.

Vanwege het benigne karakter heeft een leiomyoom een uitstekende prognose. We zullen onze patiënte vervolgen middels een jaarlijkse cystoscopie. In het geval van recidief zullen we de afwijking opnieuw chirurgisch verwijderen.

\section{Conclusie}

Deze casus beschrijft de acute presentatie van een zeldzame aandoening: een leiomyoom van de blaas. Andere tumoren die uitgaan van de blaaswand zijn neurofibromen, sarcomen, paragangliomen, schwannomen en lymfomen. MRI kan een belangrijke rol spelen in de differentiatie hiertussen. In deze casus hebben we in een acute setting door middel van chirurgische resectie de patiënte gediagnosticeerd

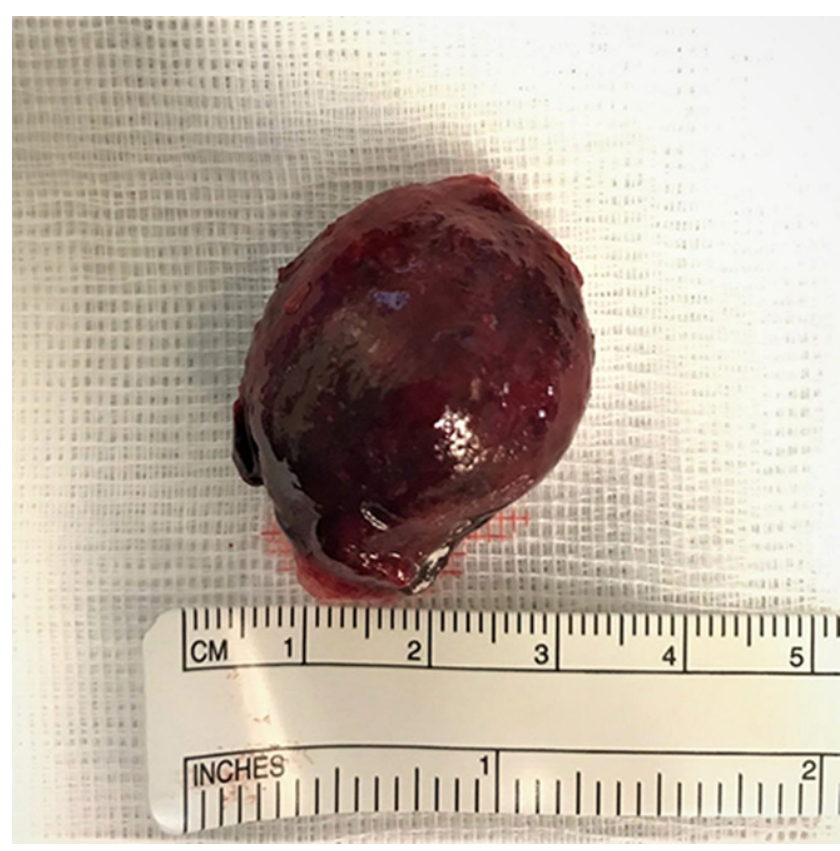

Figuur 4 Het leiomyoom na chirurgische resectie

en behandeld. Het is belangrijk om hierbij de ureterostia in acht te nemen.

Open Access This article is distributed under the terms of the Creative Commons Attribution 4.0 International License (http:// creativecommons.org/licenses/by/4.0/), which permits unrestricted use, distribution, and reproduction in any medium, provided you give appropriate credit to the original author(s) and the source, provide a link to the Creative Commons license, and indicate if changes were made.

\section{Literatuur}

1. Jain SK, Tanwar R, Mitra A. LUTS and coexisting bladder and uterine leiomyomata: a review of two cases. Rev Urol. 2014;16(1):50-4.

2. Cornella JL, Larson TR, Lee RA, Magrina JF. Leiomyoma of the female urethra and bladder: report of twenty-three patients and review of the literature. Am J Obstet Gynecol. 1997;176(6):1278-85.

3. Sudhakar PJ, Malik N, Malik A. Leiomyoma of bladder. Saudi J Kidney Dis Transpl. 2008;19(2):232-5.

4. Goel R, Thupili CR. Bladder Leiomyoma. J Urol 2013;189(4):1536-7.

5. Goldman HB, McAchran SE, MacLennan GT. Journal of Urology. J Urol. 2007;177(5):1890.

Tahnee de Vringer anios urologie

dr. John B.W. Rietbergen uroloog

dr. Niels J. van Casteren uroloog 